\title{
MECHANISMS OF REPRESSION OF INTERSEX BODIES IN FILMS XXY AND EL ÚLTIMO VERANO DE LA BOYITA, AND REPRESENTATIONAL STRATEGIES OF RESISTANCE ${ }^{1}$
}

\author{
Slađana Branković
}

\begin{abstract}
Mechanisms of Repression of Intersex Bodies in Films XXY and El último verano de la boyita, and Representational Strategies of Resistance

Abstract: This paper deals with representation of mechanisms of repression of intersex bodies in film, and representational strategies of resistance to those mechanisms, developed in two films, $X X Y$ and El último verano de la boyita, by two argentine directors, Lucía Puenco and Julia Solomonoff, respectively. It is a discursive analysis of the narratives and analysis of technical aspects of the two films, which aims to determine in which ways are representational strategies of resistance constructed, how they interpret relations between medical and social norms about sex/gender, medical and social violence against intersex people, and form critiques of medical and scientific discourse.
\end{abstract}

Key words: intersex, sex, gender, medicine, representation, strategy of resistance, film.

Mecanismos de cuerpos intersexuales y estrategias representacionales de resistencia en las películas, XXY y El último verano de la boyita

Resumen: El presente artículo examina la representación de mecanismos de represión de cuerpos intersexuales así como las estrategias representacionales de resistencia en dos películas, XXY y El último verano de la boyita, de las directoras argentinas Lucía Puenco y Julia Solomonoff respectivamente. El artículo ofrece un estudio discursivo de las narrativas y un análisis de los aspectos técnicos de ambas películas que intenta determinar en qué manera se construyen las estrategias representacionales de resistencia, cómo interpretan las relaciones entre las convenciones médicas y sociales sobre sexo/género, la violencia médica y social que se ejerce sobre los cuerpos intersexuales y cómo conforman críticas del discurso médico y científico.

Palabras clave: intersexualidad, sexo, género, medicina, representación, estrategia de resistencia, cine.

\section{Introduction}

Binary sex categorization as biological foundation of two genders, understood as social categories, was gradually constructed in scientific and medical discourse during

\footnotetext{
${ }^{1}$ Fecha de recepción: 15/04/2018.

${ }^{2}$ Post-graduate Student, Faculty of Political Science, University of Belgrade, Serbia; $\square$ sladjabrankovic89@gmail.com.
} 
the XVIII century (Laqueur 1992: 149-150). It presents one of the basic characteristics of the Western culture, and is deeply rooted in its juridical, linguistic, medical and other norms, which shape the experience of people who do not, bodily or otherwise, fall clearly into those two categories (Fausto-Sterling 1993: 20-21; Karkazis 2008: 11). Accumulation of medical and scientific knowledge about the body and development of specific medical technologies was followed by pathologization of the intersex body, which is currently predominantly being diagnosed and categorized under the term disorder of sex development ${ }^{3}$, and accordingly medically treated in order to fit in one of the two naturalized categories of male and female (Dreger 2003: 151-152; Karkazis 2008: 7). Due to that, medicine and science are, from the 1990s onward, been recognised by feminist and intersex activists, theorists, bio-ethicists and others as one of the major mechanisms of repression of intersex people (Chase 2006, 305). Since medicine represents one of the main discursive elements which shape lives of intersex people and produce meanings which play an important role in our understanding of gender, sex and intersex, it has also strongly influenced representations of intersex characters on film (Stam 2000: 182-183, 189). Because they disturb established boundaries of binary sex/gender, in the domain of visual arts, non-normative (and intersex) bodies are either suppressed or represented as monstrous, freakish and impure, thus constituting an area of radical difference in order to establish the boundaries of humanity and normalcy, and maintain the established sex/gender norms. Accordingly, in the area of narrative film, non-normative bodies and identities have been represented rarely or in ways which confirm their social inaptitude and inadequacy, as exceptional

\footnotetext{
${ }^{3}$ Disorder of sex development (DSD) was defined and accepted by Consortium on the Managment of Disorders of Sex Development, consisting of ISNA members, clinicians, bioethicists and surgeons in 2006, and promoted through Clinical Guidelines for the Managment of Disorders of Sex Development, intended for pediatric physicians, surgeons and obstetricians (Spurgas 2009: 102).
} 
medical cases ${ }^{4}$, pathological deviations and degenerates ${ }^{5}$, thus taking part in production of negative meanings which shape understandings of intersex bodies of wider population (Milanović 2015: 53-54; Gržinć 2002: para. 9).

Since meanings and power relations are never permanently fixed and unchangeable (Hall 2003: 21-22, 32), practices of visual and film representations always contain a possibility for their subversion and rejection. The gaze from the marginal positions can give us a different perspective on established social norms, formulate their critique, and create potential for alternative ways of conception and representation of intersex people (Amato 2016:50). With that in mind, and considering the importance of medical discourse and representational strategies to intersex issues, role they play in shaping intersex experiences and popular understandings, this paper aims to examine two examples of critique of medical practice, as mechanism of repression of intersex bodies, in film, and representational strategies of resistance to it, which they aim to constitute. Applying discursive analysis of the narratives of the two films, as well as analysis of deployed aesthetic and technical choices, it aims to determine which are the possible methods of constituting critique of dominant medical discourse and violence it produces, and ways of representing intersex people as active agents who resist violence and discrimination, in film. Theory of performativity of sex/gender developed by Judith Butler (Butler 1990), theory of the gaze developed by Michael Foucault, and feminist film theory, in particular works of Laura Mulvey and

\footnotetext{
${ }^{4}$ Intersex people are often presented as curious cases in television medical dramas, such as: Dr. House (David Shore 2006, "Skin Deep"), Chicago Hope (David Kelley 1996, "The Parent Rap"), Emergency Room (Michael Crichton 1998, "Masquerade") etc. (Amato 2016; 241-245).

5 For exhample as a psychopatic murderer in Terror Firmer (Lloyd Kaufman 1999), or in the film Tintomara (Hans Abramson 1970).
} 
theorizations of masculine and voyeur gaze in cinema, present theoretical basis of this paper.

\section{Mechanisms of repression and strategies of resistance in films $X X Y$ and $E l$ último verano de la boyita}

Mechanisms of repression and control of intersex bodies are important structural elements of two argentine films $X X Y$ (2007), from the author Lucía Puenzo, and $E l$ último verano de la boyita (2009), from the author Julia Solomonoff. ${ }^{6}$ With their creative conceptions, different symbolical references, technical choices, modes of framing and composition of planes and shots, through their films the two authors constitute a critique of scientific and medical discourse, critique of their invasive gaze and ways of acquiring and constructing knowledge about the body. By use of these methods they conceptualize intersex as a place of resistance, by linking agency with, otherwise heavily objectified and passivized, intersex body. Considering that medical practice and scientific discourse represent basic mechanisms of control and correction in the context of regulation and repression of intersex bodies (Fausto-Sterling 1993: 24), which thereby also give scientific ground and justification to other institutional structural elements of society, such as juridical, educational and religious, who further (re)produce dichotomous system of sex/gender as a norm, it represents an important target of critique of both analysed films. Both films are concerned with physical and symbolical violence of binary differentiated cultural environment, as well as with roles

\footnotetext{
${ }^{6}$ Both films are recognized as part of the Nuevo Cine Argentino, argentine film production which is, starting from the mid-1990s, characterized by new ways of funding, production, distribution, and its focus on the exploration of less visible social mechanisms (Peidro 2013: 70-71; Shaw 2013: 166).
} 
of different structures of society and practices of signification in the production and justification of said violence. Gaze, as a condition of control and disciplinary tool, which looks for deviations from the norm and strives to remove them (Foucault 2003: 89), as well as an important concept in film theory, is one of the main methods for the constitution of critique and strategies of resistance in two analysed films. It is a method of construction of different ways of observation and perception, which are different from the dominant medical and masculine forms of observation in film (Mulvey 1999: $62-63)$.

\section{1. $X X Y$}

Film $X X Y$ is based on a short story Cinismo written by Sergio Bizzio, and on a comprehensive research and interviews the author Lucía Puenzo undertook with geneticists, activists, parents of intersex people and intersex people themselves (Tehrani 2008 , 4). It depicts five days in the life of intersex Alex, who had not been subjected to normalizing surgeries, but is under a hormone therapy which aims to keep their ${ }^{7}$ body in the frame of the assigned female sex. Film is concerned with the events during the visit of the surgeon Ramiro, his wife Erika and his son Alvaro, who come on an invitation from Alex's concerned mother Suli, with the aim to rethink their the choices they made in rearing Alex and possible surgical intervention on Alex's body.

Surgical alteration and marginalization of intersex body, thematized in the film, is based on a discourse which marks certain bodies as unnatural, abnormal or

\footnotetext{
${ }^{7}$ Since definite positioning of the character of Alex in the binary sex/gender system is not given in the film, I will use neutral gender pronoun singular "they".
} 
monstrous, those who disturb the order and are thus defined as sick (Frohlich 2011: 160). Pointing to a "strange cultural silence" and a lack of fictional narratives about intersex issues and intersex individuals, author Lucía Puenzo, emphasizes that the film is not imagined and realized with the intention to present a certain medical case, nor does it strive to medical realism, but is imagined as a move away from the clinical gaze and its ways of observation, and is focused on the relations and connections of different characters in the film, especially those of intersex protagonist Alex and their guest Alvaro. Presentation of medical discourse in the film and its role in construction of reality of intersex subjects functions as a critique of the practice of interpretation and deliberation of intersex exclusively through science and medicine, and their terminology ("Director's Statement" 2008: 3). Gaze as a tool of objectification and control, but also a tool of resistance, is constructed through a series of dialogues, shots and scenes, which are connected by different motives, such as drawings, photographs, scientific texts, knives and cutting (Zamostny 2012: 56).

Scientific/medical discourse is represented in different ways by two characters: Ramiro, a surgeon specialized in correction of abnormal bodily characteristics, and Kraken, a marine biologist. Ramiro, mirrors dominant discourse of medical practice, while Kraken, represents an example of a possible medical regiment based on different ethical principles. Ramiro, whose character is created as a counterpart to Kraken, represents a dominant cultural order and medical discourse, and comes from Buenos Aires, which, in the context of Argentina, is the centre of social power and a core of mentioned order in which institutional medicine represents authority in regulation of intersex bodies, which it defines as sick (Karkazis 2008:10-11). Masculinist, normative, medical gaze of Ramiro is presented as a key link in the mechanism of repression of 
non-normative body, gender and sexuality. Ramiro's character is introduced from the perspective of his son, Alvaro, who sits on the back seat of a car, hence from a subordinate position in a traditional spatial distribution of power in a family vehicle. Ramiro is shown while studying Kraken's book Origenes del sexo (Origins of sex) and documents, which, as it is later made clear, are Alex's medical files, whose photo Ramiro tries to keep out of Alvaro's sight. The scene thus confirms Alvaro's subordinate position and symbolically points to unequal distribution and availability of knowledge, and a privileged position of medicine in the power/knowledge regime (Zamostny 2012: 195). Ramiro, for whom Alex presents an interesting medical curiosity, illness, and bodily deformity that needs to be corrected, i.e. a body on which he expresses his power and talent, crucial to his identity, is getting to know Alex primarily through scientific studies and their medical files. The image of Ramiro studying documents and ultrasound images of Alex repeats after he arrives to Kraken's ranch with his family. This time, he is shown drawing and considering possible ways of surgical correction, which is hinted by a line, imprinted on the paper by Ramiro's sharp movement of the hand. This scene also describes the character of normative medical gaze which has a power to categorize and decide (Foucault 2003: 89), and which presents the condition of intervention on, and control of intersex body. The threat which his gaze presents to Alex, and the relation of the gaze and intervention is most clearly implicated in the scene which describes the only close encounter of Alex and Ramiro in the film. In this scene, which begins with a depiction of Ramiro cutting a piece of meat, camera follows his gaze and passes from the meat to Alex, who enters the room and drinks milk. Ramiro's gaze, which is erotically charged, examines Alex's body, but is abruptly interrupted in its objectifying process by Alex's uncomfortably direct and 
ambiguous question “¿Te gusta?” (“Do you like it?”). The following explanation that the question refers to their house and not to their body doesn't reduce the tension and uncomfortable eroticism of the scene. The next question directed at Ramiro "¿Abrir cuerpos te gusta?" (“Do you like opening bodies?”) creates a more clear connection between Ramiro's meat cutting activity and potential surgical intervention on Alex's body (Zamostny 2012: 196).

Although Kraken and Ramiro represent dominant masculine figures and are representatives of scientific/medical discourse, their characters are very minutely constructed as opposites. Even though first depiction of Kraken in the film, as a scientist who dissects and categorizes an animal, also points to the invasive character of scientific/medical gaze and modes of knowledge production, his approach is constituted as decidedly different from Ramiro's in the further course of the film. Kraken leaves the centre of social power, Buenos Aires, thus rejecting the intrusiveness of medicine which treats his child as malformed rarity, wants to visually record and document its birth and finally surgically correct it. He goes to live in the periphery in a more socially liberal way, characterized by acceptance and understanding of differences as natural diversity (Simić 2009: para.11). His relation to Alex is in accordance with basic principles of intersex activism, related to issues of irreversible surgical alterations of infants, and freedom of choice and independence in decision-making process considering bodies, sex and gender of intersex people (Zamostny 2012: 195). Unlike Ramiro, Kraken's approach to his profession, as well as to Alex, is primarily based on the care for wellbeing of Alex and animals, mainly turtles, with whose preservation he is concerned. The described scene of a close encounter of Ramiro and Alex in the kitchen, together with the following scene, which closer depicts Kraken's professional engagement, 
constitutes a contrast of their characters and approaches to their work and bodies they treat. In this following scene, Kraken is depicted as he hurries down to the dock in order to provide help for two turtles injured by a drift net and later repairs the injury of a turtle which lost its flapper. Turtle's injury, because of which, as Alex states, it will never be able to return to the sea (“...nunca más va a volver al mar.”), symbolizes the violence of culture against nature, analogue with the violence of medical practice against intersex body, which implicates that surgical interventions are mutilations and points out to their irreversibility. Unlike Ramiro, Kraken is not the one who does the mutilation but the one who does the remedy. Except for these symbolical references, normalizing surgical interventions are clearly defined as castration by Juan, a character who has personally experienced them, and later, by his own will, transitioned from the assigned female to male sex/gender. Apart from the clear judgment of the medical practice, Juan's introduction in the narrative also has a purpose of providing the necessary information for Kraken, which he needs in order to constitute the best possible approach to Alex. This emphasizes the importance of availability of all information to parents in the decision-making process and importance of the change of medical approach to intersex people. After learning that Alex no longer takes hormones, meant to control their bodily development, Kraken starts perceiving Alex as male and, unlike Ramiro, doesn't turn to medical knowledge, but questions his own decisions and acts, and looks for advice and solution in the experience of other intersex people, instead of doctors (Fernandez et.al 2013: 65-67). Accordingly, through the entire course of the film, Kraken is presented as a person who protects Alex, cares for their wellbeing and, finally, allows a true freedom of choice, instead of pseudo democratic one between two pregiven options, thus completely rejecting the traditional role of the father whose acts are meant to be 
repressive and corrective (Simić 2009: 5). Different representations of Ramiro and Kraken, as representatives of scientific/medical discourse, illuminate the ways in which science and medicine can approach and treat nature; they can violently intervene in nature or can keep a distance and protect it. In this way a request for re-examining current medical practices and their ideological grounds is constituted, as well as the request for a constitution of different ethical principles in medicine (Frohlich 2011: $165)$.

In its examination of repressive mechanisms, film $X X Y$ shows that rejection of surgical normalization and pseudo democratic choice between two pregiven options, however, isn't a simple and safe choice, but a choice which activates other links in the mechanism as a response. Given that science and medicine are inextricably connected to social power relations, and that the ruling social conventions are based on the same ideological principles which find their foundation and justification in scientific discourse, evasion of institutional regulation triggers activation of social violence (Shaw 2013: 135-137). Physical attack and a rape attempt on Alex by a group of local young fishermen, who are equally uninterested in Alex's wellbeing as well as in that of the turtles whose empty shells they leave on the beach short before the attack, thus symbolically predicting it, with their analogy to medical practices clearly define those practices as violence. "Quiero ver, nada más...¿A ver qué tenés?” (“I just want to see, nothing more...I want to see what you have.") as stated by the leader of the bullies, defines the invasive gaze and categorization, which it shares with medical practice, as acts of violence, which lead to further endangerment of bodily integrity, to a rape attempt in one case and to surgical alteration, i.e. mutilation/castration in another. Violence on Alex as films breaking point, which leads to denouement of the narrative, 
also triggers the final confrontation and escalation of differences between Kraken and Ramiro. Protective Kraken acts impulsively and provokes a conflict with the attackers, while Ramiro, taking the position of a mediator, tries to stop him. Ramiro's resemblance to the attackers is implied in his attempt to protect them by positioning himself between them and Kraken, and is verbalized by Kraken with a sentence "Vos sos igual que ellos, ipeor que ellos!" ("You are just like them, worse than them!") (Zamostny 2012: 196). Kraken's words also point out to proportions and depth of influence of institutional violence, in opposition to the violence of local fishermen, because medical practitioners cannot be held accountable, juridically or otherwise, due to protection and justification which discursive power of science/medicine provides. Social violence, although more explicit in its form and legally punishable, in this case doesn't have the depth and irreversibility of institutional violence of medical discourse, which finds its justification in ideas and norms which it produces and defines as natural and neutral (Shaw 2013: 135-137).

Although Alex represents the margin and suffers violence, their character is in no way passive or constituted as a victim, but builds its agency and gives resistance with to them available resources. Attempt to control the visibility of their own body and the gaze from the margin, which constructs a different picture and a different approach to the intersex issue, present the basic means of the strategy of resistance to the dominant repressive discourse. "Prohibido pasar" (“Access forbidden"), a sign which stands on the gates to Kraken's ranch, which Alvaro clumsily closes after their arrival, triggers a series of motives and images of ambiguous meaning. These can be interpreted as illustration of marginalization, hiding and repression of non-normativity, as well as a constitution of borders of visibility by an intersex subject who resists the objectification 
of the normative gaze. In the following sequence which depicts arrival of Ramiro, his wife Erika and Alvaro to the house of Kraken family, camera is positioned in the line of Alex's view, defining them as the bearer of the audience's gaze, despite of their marginal position. Alex is placed in a dark space under the staircase of the porch, at the same time hidden and protected from the reverse look of the visitor, whom they secretly watch. Aside from defining Alex's position as at the same time a place of marginalization and a place of resistance and control of their own visibility, this depiction also refers to voyeur gaze of cinema audience, which is traditionally linked with masculinization of their position in the context of mainstream film production, by which identification with the dominant male characters is imposed (Mulvey 1999: 122; Stam 2000: 174-175). By positioning the camera in the line of Alex's gaze, audience is placed in the position of the marginalized protagonist of the film, thus privileging their point of view, the marginalized figure is placed in a subject position and the traditional dynamic of looks, arranged by the heteronormative gender hierarchy, is reversed (Mulvey 1999: 62-63). Although, after climbing the stairs of the porch, Alvaro notices Alex from above, through the crack in the floor, and in spite of Alvaro's higher spatial position, Alex remains the bearer of the look because the exchange is initiated and terminated by Alex, who stays in line with the position of the camera (Frohlich 2011: 163). Further developments in the scene continue to expand the theme of constitution and control of their own visibility by Alex, with the series of shots recorded from the point of view of Alvaro, who examines the inside of the house and Alex's room. The shots emphasize photos, which depict Alex, and modified dolls in their room. Photos which document age progression of Alex also depict the progression of discomfort in front of the camera and their gradual limitation of the visual field by hiding their face 
with a hand or by turning the head away. Aside from the photos, in their room, Alvaro also finds dolls, whose "normal" bodies Alex had modified according to their own anatomy. This can be interpreted as an intervention into the dominant discourse, which constitutes Alex's agency and points to the subversive potential of non-normative forms of embodiment (Peidro 2013:86; Estrada-Lopez 2014: 438).

Considering that genital anatomy of Alex is never shown in the film, the curiosity of the audience is awaken by denying them the look from the view point of the attackers and medicine, thus pointing out on how, by whom and to what purpose is intersex body being exposed for viewing. Denying the access to the full anatomy of Alex has a purpose to avoid objectification and reduction of the narrative to a sensationalist moment of uncovering and seducing the voyeur gaze of the audience (Frohlich 2011: 162-164). A shot which depicts Alex while they sleep, lying on their stomach, with its composition and positioning of the body, inevitably evokes the classical theme of "sleeping hermaphroditus". Considering that the lying figure of Alex doesn't contain the kind of sexuality embodied in the ideal combination of male and female anatomy of classical depictions, this shot can be interpreted as an illustration of the changed relation to the intersex body, which is, from the XIX century, being shaped under the strong influence of medical discourse. In a described shot, Alex wears small shorts, thus limiting the field of visibility to the normative gaze, and denying the satisfaction to the voyeur gaze of the audience, with the aim to control and prevent objectification, whether it is connected to sexualisation and fetishization or to pathologization of non-normative embodiment. The shot, once more, points out to the shame and embarrassment that is linked to the "abnormal" body, as well as to Alex's attempt to control the visibility of their body. As Alex wakes up, movements of their 
body, which evoke images of the waves in the previous shot, make a brake with the passivity of the evoked classical sculptures and immobile bodies which are exposed to the gaze, thus also emphasizing Alex's agency, fluidity and unidentifiable character of their sex/gender. The only form of visualisation of their full body is presented from their perspective, in the way they experience it, through the interventions on dolls and drawings in the notebook which Alvaro finds in their room. Unlike objectifying and schematic ultrasound depictions and Ramiro's drawings, Alex's drawings represent complex depictions of their understanding of the changes through which their body goes through by entering the puberty and depictions of their emotional and psychological states. One-dimensionality and objectification of anatomical drawings and depictions in medical manuals, to which a scene, in which Alvaro tries to draw a "strange bug" ("un bichito raro"), refers, Alex recognizes as threatening and risky, particularly when we have in mind that the epithet "raro" ("strange") is through the entire course of the film being linked to Alex. Their discomfort and resistance to normative gaze is expressed by killing the bug which is followed by the comment "¿Qué sabés vos de las especias de mi casa?" ("What do you know about the species of my house?"), thus questioning the legitimacy and abolishing the access to Alvaro's normative gaze, which, in accordance with medical observation of intersex body, results in categorization in the field of strange, abnormal, different, the Other (Frolich 2011: 164; Zamostny 2012: 200).

Control of visibility plays an important role in the Alex's and Alvaro's relationship, which begins with previously described exchange of looks through the crack in the floor of the porch. In the film, camera intermittently changes position between Alex's and Alvaro's point of view, or depicts both characters together in the shot, side by side, thus building a balanced relationship. However, always present 
anxiety which Alex feels around people who want an insight into the peculiarities of their body, who reduce their whole personality to it, and/or wish to correct it (Frohlich 201: 167), as well as the presence of a sexual tension and a desire for intimacy, complicates the relationship and dictates the dynamic of looks and visibility between the two protagonists. Alex sets boundaries to Alvaro's gaze, in an attempt to build a relationship which is not based on fetishization of their body. Therefore Alex controls and sets the conditions during their sexual encounter, disenables Alvaro's voyeur attempt to inspect their body in the following scene, and determines the moment and the way in which they expose their body to Alvaro. In a scene which begins with a depiction of Alex's naked body in front of the mirror in their room, after the sexual intercourse with Alvaro, composition of the shot, light and shadow makes Alex's genitals invisible to audience and to confused Alvaro who stands in front of the house and watches Alex through the window. When Alex notices his gaze, they turn off the light, by which they establish the control of their visibility, completely protects themselves from Alvaro's gaze and dismisses his voyeur objectification. When Alex, in the final part of the film, short before Alvaro's return to Buenos Aires, reveals their genitals to Alvaro, they do it by their own will and in a way which prevents satisfaction of voyeur desire. By previously asking the question “¿Qué te da más lástima... no verme más o no haberla visto?" ("What makes you feel worse... not seeing me anymore or that you didn't see it?"), and to which Alvaro doesn't give an answer, Alex tries to determine if Alvaro evolved and overcame the fetishist relation to them, i.e. is a complex and intimate relationship in binary differentiated world possible for them (Frohlich 2011: 167; Zamostny 2012: 200-201). 
Although this hiding away of genitals indirectly illustrates marginalization, hiding and silence around the body on which shame is being imposed, Alex doesn't succumb to the influence of this discourse and controls their visibility primarily in order to protect the integrity of their body and identity. Not only does Alex call into question the imposed silence by asking Kraken “¿Sy soy so especial, por qué no puedo hablar con nadie?" (“If I am so special, why can't I talk to anyone?"), but also rejects to stay quiet about the attack on them by the group of young local fishermen. They decide to report the attack to the police, despite Kraken's warnings that "the whole world" will know about their difference afterwards, which could lead to further discrimination and violence by the community, but also to a potential change in the treatment of intersex people. The emphasis on Alex's independent decisions about their identity, body and presentation, as well as the decision to reveal their difference to a wider community, presents an attempt to construct intersex body as a place of resistance defined by agency.

\subsection{El último verano de la boyita}

Film El último verano de la boyita, from the director and scriptwriter Julia Solomonoff, follows events during one summer in the lives of girl Jorgelina and intersex boy Mario. The narrative is told from the perspective of Jorgelina, a prepubescent girl who tries to understand the changes which adolescence brings with it. It is focused on her approach to Mario, who lives and works on a farm which Jorgelina visits with her father and farm owner Eduardo. Mario is raised as a boy, wasn't 
subjected to surgical or hormonal treatment and wasn't informed about his bodily difference, which he, by entering the puberty, discovers by himself, and together with Jorgelina tries to decipher bodily and gender norms of the adults, which hinder their development.

As in the case of the film $X X Y$, forms of framing, dynamics of looks between different characters, and lining the point of view of the camera with the point of view of the character on the margin, present important aspects of the film El último verano de la boyita in an attempt to construct a different way of representation and a different approach to intersex issues and issues of gender non-normativity. To this end, in technical and aesthetic aspect, camera stays at the height of the children's view and constructs a narrative from Jorgelina's position, which, considering that Jorgelina is a child and a female with non-normative gender expression, presents a marginal position in the social hierarchy (Shaw and Martin 2012: para.14).

By privileging Jorgelina's perspective an alternative approach to the problem of non-normative sex/gender is built and constructed in opposition to the medical approach, which is represented in the film by medical books which Jorgelina secretly studies and the figure of her father, a gynaecologist Eduardo. Jorgelina, who is from the start depicted as an extremely curious character who doesn't care about the established boundaries of access to information, before the narrative starts to develop, shares everything with her older sister Luciana, with whom she has a very close relationship. After Luciana's entry into puberty, which results in her distancing herself from activities which are typical for children, and thus her younger sister, Jorgelina tries to understand physical changes which come with adolescence and cultural norms which 
shape acceptable, binary differentiated behaviours and embodiments of adult subjects. She tries to understand adolescence as a place and a process of passing into adulthood, which all influence and change the relationship between two sisters (Vankatesh 2016: 92). Because of her sisters' distancing and constitution of a private sphere (she moves to her own room and doesn't take part in activities with Jorgelina), Jorgelina turns to her father's medical books to look for the answers, thus collapsing the traditional methods of distribution of scientific knowledge reserved for experts, adults and institutional education. A scene, in which Jorgelina is introduced in the film, depicts her as she, without permission, rummages the boxes full of books, secretly takes one of them and goes into boyita, which has a function of a safe children's space, shelter and a place of intimacy of the two girls. The book which she takes with her is her father's medical manual which contains schematic depictions of female bodily changes in different periods of life, and various schematic depictions of female reproductive organs. The depictions become more and more explicit, contain instructions for vaginal examinations and photos from operations and dissected body parts, illustrating the invasiveness of the medical gaze which causes Jorgelina's negative reaction, and closing of the book with repulsion on her face. As this scene predicts, medical knowledge and approach to non-normative embodiment will, in her view, be shown as insufficient and limited (Harris 2009; Buiting 2015: 36).

As in the film $X X Y$, medical bipolarity of normalcy/abnormalcy is emphasized, whereby every form of embodiment which sways from the two legitimate types of organic structure is being marked as abnormal (Foucault 2003: 33-36). Aside from the threat with surgical intervention, this signification also has wider social consequences closely related to understanding of gender as in nature grounded cultural manifestation 
of sex. Process of signification, influenced by medical norms, and social consequences which it produces are presented in the film with a sequence which describes a series of events which are triggered by Jorgelina, when she finds blood on Mario's saddle and pants. After she notices the blood after horse riding, not knowing that it is in fact menstruation, she supposes that Mario has a cut, and suggests to him that he asks her father for help. Mario, however, refuses medical help, and in the light of playing, conversation and building intimacy and trust in the previous scenes, entrusts himself to Jogelina and hints that he thinks that he might be physically different, that the blood is menstrual, and begs her not to tell anyone about it. As in the case with Luciana, in her search for answers about, this time male, adolescent body, Jorgelina again turns to medical books as to a known authority on the subject and the only available source of information. By comparing himself with the depictions from the book which Jorgelina secretly brought to him, Mario concludes that he deviates from the norm, and confesses to Jorgelina "No soy como en la foto...Yo no soy normal" ("I am not like in the photos...I am not normal"). Labelling bodies as abnormal, i.e. diagnosing them, represents a first step in the process of normalization of intersex body. Although, due to specific socio-cultural context, Mario evades the discipline of medical practice, the threat of normalization always stays present, which causes non-normative body to hide itself, thus constituting a part of mechanism of repression and marginalization of intersex body (Peidro 2013: 78; Buiting 2015: 41).

Eduardo's acts, as those of a representative of the medical authority, reveal ethical issues of norms which medicine constitutes and which in its practice follows. Because of her concern for Mario's health, and in search for information which could situate Mario's bleeding in the domain of normal, harmless part of maturing process of 
a male body, Jorgelina shares Mario's secret with her father. During Eduardo's examination of Mario, his confused and concerned look defines Mario's genitals as problematic and later presents it to Mario's mother as urgency which demands a prompt resolvement and medical treatment. Due to his position of authority to whom, as he considers, these kind of cases need to be reported, Eduardo experiences Mario's body as an unacceptable oversight and violation of the laws of medical disciplinary mechanisms. This is confirmed by his critique of Mario's parents, who based their reactions on Mario's good health and ignored his physical non-normativity. His insistence on revealing and finding solution to newly developed situation, leads to physical violence against Mario and to a change of Mario's position in the family and in the community when the truth about his body reaches his father ${ }^{8}$. Eduardo's concern contrasts the indifference expressed in the scene which comes before the described sequence, when Jorgelina notices that a group of local boys and his future rival in horse racing is bullying Mario. In this case, Eduardo ignores Jorgelina's concern with the discomfort Mario has to endure, which calls into question sincerity of Eduardo's later concern for Mario, and reveals medical practice as oriented only to preservation of norms which it constitutes, instead to preservation of wellbeing of the patient (Buiting 2015: 41-44; Karkazis 2008: 289). Although Eduardo, after the examination, tells Mario not to worry ("No te preocupes...no es nada"), the next scene, in which we see Mario, shows that there is a cause for concern, although the threat to his wellbeing is not internal, on which Eduardo's gaze is centred, but external, which Eduardo again ignores. The scene begins with a long high-angle shot of a quiet landscape, followed by

\footnotetext{
${ }^{8}$ It stays unclear how much did Mario's father knew about Mario's body, Mario's visits to the doctor and if his anger was caused by the revelation of Mario's secret to others or by Mario's decision to keep it a secrt from his father.
} 
Jorgelina's whispering a prayer, whose contrast to the following shot is reinforced by a jump-cut to an image of a small window of a warehouse in which Mario lives. Through the window we see silhouettes of Mario and his father Oscar, and, telling from their movements, we find out that Mario is being beaten. After Jorgelina's prayer is interrupted by an unrecognisable noise, she goes to warehouse where she finds badly beaten Mario in bruises and wounds. Afterwards, Oscar takes away the privileges reserved for men from Mario, he is consequently excluded from the spaces defined by maleness and the race in which he was supposed to take a part, and which represents a kind of ritual of passing into adulthood and proof of their masculinity for boys in the context of rural Argentina (Slatta 1986: 97-98; Buiting 2015: 43; Vankatesh 2016: 104).

Described scenes illustrate the way in which medical norms, binary differentiated gender roles and sex/gender hierarchy function as a symbolical and ideological basis for surgical normalization, physical violence, exclusion and discrimination of intersex body, i.e. for different acts of repression that work in accord, although on different levels, and function as links in a specific system of repression. Medical norms which give scientific justification for binary conceived idea of sex/gender, and function as disciplinary control mechanism which maintain established sex/gender hierarchy, label non-normative body as abnormal and define it as a threat to which gaze and observation are directed.

Unlike normative medical, Jorgelina's curious gaze doesn't bear with it components of control, discipline and hierarchy, but represents a different sort of cognition, different from scientific, and is tied to care and intimacy (Shaw and Martin 2012: para.13; Buiting 2015: 49). Her examination of the unknown and a will for 
knowledge is aimed at building and preserving intimate relations with Luciana and Mario, and is illustrated in various scenes which can be interpreted as analogies or pairs, and which firmly link Jorgelina's gaze to intimacy. After she finds hurt Mario shrivelled in his bed in the warehouse, Jorgelina stops at first, observes him for a few moments, and then comes to him, sits on the bed and puts her head on his shoulder. This scene evokes an earlier one, in which Jorgelina and Luciana are lying in a sunbed, and which is a part of the sequence which describes the relation of the two sisters. After the quarrel and a fight between two sisters, caused by Lucana's distancing from Jorgelina and childish activities, they are shown dozing on a sunbed one by the other. After a dog disturbs Jorgelina's peace, she wakes up, observes Luciana for a few moments and then hugs her and puts her head on her sister's shoulder. Likewise, her observation and examination of the spaces in which Luciana and Mario live, her keeping track of renovations which take place in Luciana's room and examination of a rustical warehouse corner which presents Mario's private space, examination of handmade toys and books which belong to him, define Jorgelina's approach as more complete, interested in all aspects of their personalities as well as in norms which shape those spaces and in changes through which the two adolescents go through. By privileging Jorgelina's point of view, film rethinks sex and gender norms from a child's perspective, i.e. a person who isn't completely familiar with the symbolical universe of a particular culture and its social conventions, still hasn't fully internalized imposed norms and thus contains a distance which bears a potential for a different conception and a different approach to issues of sex/gender. Jorgelina's rejection of medical interpretation of Mario's body, illustrated in a scene in which she closes her ears when Eduardo tries to explain to her Mario's embodiment with medical terminology, implies 
a possibility of rejection of repressive medical approach, leaves a space for a different one, different regime of thinking, acceptance of intersex persons, and intersex experience which isn't marked with trouble, violence and fear (Shaw and Martin 2012: para.13). Children's, marginal way of acquiring knowledge, privileged in the film, can be interpreted as overcoming of the grammar of repressive hegemonic regiment, while the position of the child symbolizes the new beginning and a possibility for a conception of a different future (Jose Punte 2014: 2). Children's, Jorgelina's and Mario's, way of acquiring knowledge is opposed to the scientific regiment of knowledge, as the culturally privileged form of revealing the Truth. It points out to its flaws and reveals his incorporation into relations of power which it produces over again and maintains, as well as its role in the production of certain embodiments as abnormalities/pathologies/otherness (Terry 1995: 135-137).

As well as in the film $X X Y$, audience is denied the medical point of view and a visual depiction of part of Mario's anatomy which are, in the dominant discourse, perceived as problematic. In this way his objectification is disabled and a potential for his agency constructed. Jorgelina's gaze and the way in which she gets to know Mario, opens another possibility for a different approach to an intersex subject, by which the character of the person is not reduced to their body, and the body is not defined by binary parameters. Mario's agency, whose gaze also constitutes an alternative to the medical one ${ }^{9}$, is recognised in taking over the control, resistance to imposed norms and dominant male figures, to father Oscar and the rival in the race, who are positioned higher in the hierarchy of the community. Although, in the beginning, he silently

\footnotetext{
${ }^{9}$ Unlike Jorgelina's, whose way of acquiring knowledge contains a strong conversational component and is defined by having access to medical literature, Mario's is direct, relies exclusively on his own experience and senses in an environment in which he has direct access to life cycle and extremes like birth and death; he has a more direct knowledge about life but is mute (Shaw and Martin 2012).
} 
endures violence, new social role and observes as his horse is being sold to his rival together with his opportunity to take part in the races, he doesn't accept this new situation, but takes things into his own hands, fights for his position and in that process redefines this discriminatory masculine position and opens it to different possibilities. After being assigned to a new role, culturally defined as feminine, and denied the right to take part in the races, Mario runs away from the house, and comes back short before the races begin, retrieves his horse and wins the race. As he retrieves his horse and takes his position on the start line, a betting organizer writes his name on the board, and thus symbolically includes him in the domain of hegemonic masculinity. However, Mario refuses this inclusion in the domain which he discovered to be violent and discriminatory, by ignoring the affirmation of the audience and invitations to be photographed after winning the race. Mario and his horse continue their gallop, avoid the masculine gaze of the camera and confirmation of his identity by the hegemonic masculine regime, thus also refusing to recognize it as authority. Mario's act of resistance and his winning the race point to a potential for intervention into the dominant discourse, and disturbance of one, but grounding, norm of hegemonic masculinity, the normative embodiment. It opens its borders and leaves space for further deconstruction, redefinition and different conceptions of sex/gender (Vankatesh 2016: 106-109).

\section{Conclusion}

Both films identify specific mechanisms which in different ways and on different social levels repress intersex body. Medicine and science, as normative 
practices, in both films, and especially in $X X Y$, are identified as key links in a repressive system, which classify intersex body as abnormal, produce and give foundation and explanation to cultural signifiers of intersex bodies as monstrosity, abnormality etc. Moving away from medical discourse, as well as from representations of marginal personalities as helpless victims ${ }^{10}$, agency of the two intersex protagonists of the films is being built, while open endings of the two narratives leave the possibility for intervention into the dominant discourse and change of binary sex/gender paradigms. Control of visibility, the gaze from the margin, different ways of acquiring knowledge and resistance of intersex protagonists to violence, discrimination and dominant figures in the social hierarchy, constitute strategies of resistance to the repressive regiment. Both films, with their move away from usual ways of representation of intersex people which are defined by medical discourse, constitute new, different representational strategies, and are thus important achievements in the area of film production. Although unable to completely exclude the presence of medicine, their clear critique of it presents an important point in history of visual representation of intersex people.

\section{References}

Amato, Viola. 2011. Intersex Narratives: shifts in the Representation of Intersex Lives in North American Literature and Popular Culture. Bielefeld: transcript.

Buiting, Lotte. 2015. "Childhood as Refuge from Gender Performance in the Last Summer of La Boyita". Red Feather Journal, 6 (1): 36-54.

\footnotetext{
${ }^{10}$ Persons with non-normative sexualities and/or gender identities, as well as women victims of violence, are often stereotipically represented as helpless, unable for resistance and prone to committing suicide. More in: Rob Cover, Queer Youth Suicide, Culture and Identity, Ashgate, Farnham and Burlington, 2012; Samuel Clowes Huneke „The gay suicide stereotype kills gay people and it must end“, Aeon, 2016, on: https://aeon.co/ideas/the-gay-suicide-stereotype-kills-gay-people-and-must-end.
} 
Butler, Judith. 1990. Gender Trouble: Feminism and the Subversion of Identity. New York and London: Routledge.

Chase, Cheryl. 2006. "Hermaphrodites with Attitude: Mapping the Emergence of Intersex Political Activism”. The Transgender Studies Reader. Ed. Susan Stryker and Stephen Whittle. New York: Routledge.

Clowes Huneke, Samuel. 2016. "The gay-suicide stereotype kills gay people, and it must end". Aeon. https://aeon.co/ideas/the-gay-suicide-stereotype-kills-gay-peopleand-must-end. [13 April 2018.]

Cover, Rob. 2012. Queer Youth Suicide, Culture and Identity. Farnahm and Burlington: Ashgate.

2008. "Director's Statement”. XXY Film Movement Press Kit. New York: Film Movement.

Estrada-Lopez, Lourdes. 2014. "Deconstrucción sexual e intersexualidad en XXY de Lucía Puenzo". Bulletin of Spanish Studies, 91 (3): 419-443.

Fausto-Sterling, Anne. 1993. "The Five Sexes: Why Male and Female Are Not Enough". The Sciences, March/April 1993: 20-25.

Fernández, M.V.C., M.L. Fernández and Y.R. Castro. 2013. "Heteronormadividad, cultura i educación: Un análisis a propósito de 'XXY'”. Inersexiones: Revista de Producción Mestiza, 4: 45-76.

Foucault, Michel. 2003. The Birth of the Clinic: An Archaeology of Medical Perception. New York: Routledge.

Frohlich, Margaret. 2011. "What of unnatural bodies? The discourse of nature in Lucía Puenzo's XXY and El niño pez/The Fish Child". Studies in Hispaic Cinemas, 3 (2): 159-174.

Gržinić, Marina. 2002. "In-Between Sexes. Stranger Than Angel”. Stranger Than Angel: Dissident Bodies. Eds. M. Klonaris and K. Thomadaki. Ljubljana: Cankarjev Dom. http://www.klonaris-thomadaki.net/60grz.htm [13 April 2018].

Hall, Stuart. 2003. "The work of Representation". Reresentation: Cultural Representation and Signifying Practices. Ed. Stuart Hall. London: SAGE.

Harris, John. 2009. "Interview with Julia Solomonoff, director of El ultimo verano de la boyita". LandingPadBa. http://landingpadba.com/interview-julia-solomonoffdirector-el-ultimo-verano-de-la-boyita [13 April 2018].

José Punte, María. 2014. "Miradas que hablan: infancia y experiencia en la narrative argentina reciente". Cuadernos LIRICO, 11: 2-10.

Karkazis, Katrina. 2008. Fixing Sex: Intersex, Medical Authority and Lived Experience. Durham and London: Duke University Press. 
Laqueur, Thomas Walter. 1992. Making Sex: Body and Gender from the Greeks to Freud. Cambridge, Massachusetts and London: Harvard University Press.

Milanović, Aleksa. 2015. Reprezentacija transrodnih identiteta $u$ vizuelnim umetnostima. Belgrade: FKM and Orion Art.

Mulvey, Laura. 1999. "Visual Pleasure and Narrative Cinema". Feminist Film Theory: A Reader. Ed. Sue Thornham. Edinburgh University Press.

Peidro, Santiago. 2013. "Dos casos de intersexualidad en el cine argentino". Sexualidad, Salud y Sociedad, 14: 66-90.

Shaw, Deborah and Debbie Martin. 2012. "An Interview with Julia Solomonoff on 'The Last Summer of La Boyita",. Auteuse Theory [web blog]. http://auteusetheory.blogspot.rs/2012/05/interview-with-julia-solomonoff-onlast.html [13 April 2018].

Shaw, Deborah. 2013. "Sex, texts and money, funding and Latin American queer cinema: The cases of Martel's Nina Santa and Puenzo's XXY", Transnational Cinemas, 4 (2): 165-184.

Simić, Mima. 2009. "XXY-Interseksualni kod” ZaMirZine. http://www.umas.unist.hr/ vidos/izlozba/goranp/tjednik/XXY_interseksualni_kod .html [13.4.2018].

Slatta, Richard W. 1986. "The Demise of the Gaucho and the Rise of Equestrian Sport in Argentina". Journal of Sport History, 13 (2): 97-110.

Spurgas, Alyson K. 2009. "(Un)Queering Identity: The Biosocial Production of Intersex/DSD". Critical Intersex. Ed. Morgan Holmes. Farnahm and Burlington: Ashgate.

Stam, Robert. 2000. Film Theory: An Introduction. Massachusetts: Blackwell.

Tehrani, Bijan. 2008. “An Interview with Lucia Puenzo”, XXY Film Movement Press Kit. New York: Film Movement.

Terry, Jennifer. 1995. "The Seductive Power of Science in the Making of Deviant Subjectivity". Posthuman Bodies. Eds. J. Halberstam and I. Livingston, Bloomington and Indianapolis: Indiana University Press.

Vankatesh, Vinodh. 2016. New Maricón Cinema: Outing Latin American Film. Austin: University of Texas Press.

Zamostny, Jeffrey. 2012. "Constructing Ethical Attention in Lucia Puenzo's XXY: Cinematic Strategy, Intersubjectivity, and Intersexuality". Representing History, Class and Gender in Spain and Latin America: Children and Adolescent in Film. Eds. Carolina Rocha and Georgia Seminet. New York: Palgrave and Macmillan. 